\title{
PENGARUH ASPEK LAPANGAN PENUMPUKAN TERHADAP DWELLING TIME DI TPK KOJA
}

The Influence of Container Yard Aspect On Dwelling Time in TPK Koja

Oleh:

Uga Prathama ${ }^{1^{*}}$, Ruddy Suwandi ${ }^{2}$, Nimmi Zulbainarni ${ }^{3}$, Deni Achmad Soeboer ${ }^{4}$

${ }^{1}$ Inspektorat Jenderal, Kemenhub RI

${ }^{2}$ Pusat Kajian Sumberdaya Pesisir dan Lautan, Institut Pertanian Bogor

${ }^{3}$ Staf Pengajar Sekolah Bisnis, Institut Pertanian Bogor

${ }^{4}$ Staf Pengajar Program Studi Teknologi Perikanan Laut

“Korespondensi: uga.prathama@yahoo.co.id

\begin{abstract}
ABSTRAK
Terminal peti kemas Koja (TPK Koja) merupakan suatu entitas bisnis yang berada di Pelabuhan Tanjung Priok yang berfungsi sebagai simpul logistik perdagangan baik untuk ekspor maupun impor. Kegiatan impor di Pelabuhan Tanjung Priok menjadi permasalahan tersendiri terkait dengan lamanya waktu peti kemas mengendap di lapangan penumpukan lini 1. Kebijakan pemerintah tentang dwelling time kepelabuhanan merupakan solusi dan tantangan bagi TPK Koja, karena seluruh kegiatan yang berhubungan dengan bongkar muat peti kemas berpotensi sebagai penyumbang tingginya $d w e l l i n g$ time, faktor utama yang menjadi penentu terkait dengan $d$ wellling time di terminal peti kemas adalah lapangan penumpukan. Dari hasil penelitian yang dilakukan di TPK Koja, pada tahun 2016 kondisi luas lapangan penumpukan yang digunakan sebesar 6,90 ha dengan waktu $d$ welling time selama 3,8 hari dan kapasitas YOR 58,47\%. Penelitian ini menggunakan metode deskriptif, berdasarkan hasil analisis data berupa perhitungan kapasitas lapangan penumpukan. Hasil menunjukkan bahwa tingkat $d w e l l i n g$ time di TPK Koja saat ini masih cukup tinggi, untuk menunjang kelancaran arus peti kemas TPK Koja perlu melakukan perbaikan terhadap indikator penentu $d$ welling time dan mengacu pada waktu $d$ wellling time sesuai dengan kebijakan pemerintah yang berlaku saat ini.
\end{abstract}

Kata kunci: Dwelling Time Kepelabuhanan, Impor, Kebijakan Pemerintah, TPK Koja.

\begin{abstract}
Koja container terminal (TPK Koja) is a business entity located at Tanjung Priok Port that serves as a logistics trade node for both export and import. Import activities at the Port of Tanjung Priok become a separate issue related to the length of time the containers settle in the containers yard line 1. Government policy on dwelling time port is a solution and challenge for TPK Koja, because all activities related to container loading and unloading potentially as high contributor dwelling time, the main determining factor associated with dwellling time in container terminals is the containers yard. From the results of research conducted at TPK Koja, in 2016 the condition of the accumulation area used is 6.90 ha with a dwelling time of 3.8 days and the capacity of YOR 58.47\%. This research uses descriptive method, based on data analysis result of calculation of capacity of containers yard. The result shows that the dwelling time rate in TPK Koja is still high enough to support the smooth flow of container TPK Koja needs to make improvements to the dwelling time determinant indicator and refers to the dwelling time in accordance with current government policy.
\end{abstract}

Keywords: Port Dwelling Time, Import; Government Policy, TPK Koja. 


\section{PENDAHULUAN}

Pelabuhan secara universal berfungsi sebagai: (1) gate way atau pintu gerbang resmi lalu lintas barang, (2) link atau mata rantai penghubung the chain of transport, (3) interface atau tempat berlangsungnya transfer barang antar dua muka (front) terdiri dari sisi laut dan sisi darat, (4) industry Entity atau pelabuhan sebagai tempat kumpulan industry (collection of industries) yang terkait erat dengan kepelabuhan berupa usaha pokok maupun pendukung (Lasse 2014). Menurut Triatmodjo (2010) menyatakan "Pelabuhan mempunyai daerah pengaruh (hinterland), yaitu daerah yang mempunyai kepentingan hubungan ekonomi, sosial dan lain-lain dengan pelabuhan tersebut" misalnya barang impor pada industri otomotif yang masuk ke Indonesia melalui pelabuhan tanjung priok memiliki mata rantai logistik yang terintergrasi karena selanjutnya akan didistribusikan ke seluruh wilayah Indonesia, oleh sebab itu peran pelabuhan sangat penting karna merupakan simpul logistik, penentu tingkat nilai suatu produk barang dan perkembangan wilayah di sekitar pelabuhan.

Di Indonesia kegiatan perekonomian masih terpusat pada Pelabuhan Tanjung Priok yang memiliki ukuran pelabuhan terluas dibandingkan pelabuhan yang ada saat ini, Pelabuhan Tanjung Priok merupakan pelabuhan utama yang memiliki fungsi untuk melayani kegiatan angkutan laut dalam negeri dan internasional dalam jumlah besar serta memiliki peran yang strategis terhadap pertumbuhan industri dan perdagangan sekaligus sebagai sektor usaha yang memberikan kontribusi bagi pembangunan nasional, oleh karena itu sudah seharusnya Pelabuhan Tanjung Priok mampu menjamin kelancaran seluruh aktivitas di pelabuhan, namun pelabuhan tidak terlepas dari permasalahan dan tantangan yang harus segera diselesaikan, menurut Susanto (2014) menyatakan "perkiraan jumlah permintaan terminal peti kemas di tanjung priok hingga tahun 2030 akan mencapai 2-3 kali lipat dari pada kapasitas yang tersedia di tahun 2014". Permasalahan lainnya adalah fenomena dwelling time di pelabuhan (Artakusuma 2012; Argiansyah 2016; Rafi dan Purwanto 2016). Fenomena ini pertama kali muncul diawali oleh kunjungan Presiden Republik Indonesia pada tahun 2015, fungsi pelabuhan pada dasarnya adalah sebagai area transit peti kemas, namun lamanya peti kemas mengendap di lapangan lini 1 menjadikan fungsi pelabuhan tidak seusai dengan peruntukannya, hal ini dikarenakan oleh beberapa sebab utama, yang pertama adalah lamanya waktu proses pelayanan di pelabuhan, import container dwelling time memegang peranan penting karena berhubungan langsung dengan lama waktu yang harus dilalui dalam satu rangkaian proses pelayanan kepengurusan peti kemas di dalam terminal, yang kedua adalah peti kemas yang telah memiliki Surat Perintah Pengeluaran Barang (SPPB) namun masih mengendap di terminal peti kemas dalam waktu yang cukup lama, seharusnya peti kemas yang telah selesai proses kepengurusannya dapat segera keluar dari lapangan penumpukan lini 1. Apabila permasalahan tersebut tidak segera diberikan langkah perbaikan maka akan sangat berdampak terhadap kelancaran kegiatan di lingkungan pelabuhan yang lebih luas lagi (Kemenhub 2016).

Menurut World Bank dalam Seminar Nasional Peluang dan Tantangan Profesi Ekspor dan Impor Dalam Menghadapi Asean Economic Community (2015), waktu rata-rata $d$ welling time (dt) ekspor di Indonesia pada tahun 2014 sebesar 8 (delapan) hari. Sebagai perbandingan, Malaysia memiliki dt ekspor sebesar 3 (tiga) hari, Thailand 4 (empat) hari, Vietnam 7 (tujuh) hari dan Philiphines sebesar 5 (lima) hari. Sehingga dapat di lihat bahwa waktu dwelling time ekspor di Indonesia cukup kompetitif dibandingkan di negara ASEAN yang lainya.

Dalam beberapa tahun terakhir penurunan waktu $d$ welling time impor menjadi fokus utama dan menjadi salah satu prioritas kinerja pemerintah, yang bertujuan untuk menekan biaya logistik serta kelancaran arus barang di pelabuhan, kebijakan ini mengarahkan kepada seluruh stakeholder di pelabuhan untuk bekerja secara efektif, efisien dan professional sesuai dengan fungsinya agar pelayanan di pelabuhan menjadi lancar, aman dan cepat.

Kondisi saat ini lapangan penumpukan di TPK Koja dibandingkan dengan container yang masuk atau biasa disebut sebagai Yard Occupancy Ratio (YOR) telah melampaui batas standar utilisasi fasilitas sebesar 65\%. Meningkatnya arus kontainer di TPK Koja yang diletakkan di lapangan penumpukan 
diduga mempunyai pengaruh terhadap $d$ welling time impor di TPK Koja, sehingga perlu diteliti luas eksisting lapangan penumpukan impor yang terpakai dan kapasitas lapangan penumpukan impor (YOR).

\section{METODE PENELITIAN}

Teknik pengumpulan data pada penelitian ini dilakukan pada saat observasi lapangan melalui pengamatan langsung atau peninjauan secara langsung serta melalui wawancara yang melibatkan pihak TPK Koja, sedangkan pengumpulan data sekunder dilakukan untuk mendapatkan data tertulis dari TPK Koja maupun melalui studi pustaka.

Untuk menemukan makna dan menghindari pemaknaan yang salah terhadap hasil analisis yang telah diidentifikasi dalam peneliti ini, maka menggunakan wawancara dengan key informan untuk mengetahui kondisi aktual lapangan penumpukan di TPK Koja, serta untuk mendapatkan solusi dari akar pemasalahan yang terjadi, penentuan key informan atau nara sumber dalam pengumpulan data primer pada penelitian ini menggunakan metode non-probability sampling yaitu purposive sampling (sengaja), purposive sampling merupakan metode pengambilan key informan yang dilakukan secara tidak acak (sengaja), tetapi dipilih dengan pertimbangan-pertimbangan tertentu berdasarkan tujuan penelitian, umumnya pertimbangan tersebut melalui kesepakatan antara peneliti dengan key informan.

Teknik pengolahan dan analisis data dalam penelitian ini menggunakan perhitungan luas eksisting lapangan penumpukan yang terpakai dengan rumus perhitungan sebagai berikut :

$$
A=\frac{T D A_{T E U}}{365(1-B S)}
$$

dengan :

$\mathrm{T}$ : Arus peti kemas per tahun (box, TEUs), 1 TEUS $=29 \mathrm{~m}^{3}$, dan 1 box $=1$,7 TEUs.

$\mathrm{A}_{\mathrm{T}}$ : Luas lapangan penumpukan peti kemas yang diperlukan $\left(\mathrm{m}^{2}\right)$.

D : Dwelling time atau jumlah hari rerata peti kemas tersimpan di lapangan penumpukan. Apabila tidak ada informasi, bisa digunakan 7 hari untuk peti kemas impor dan 5 hari untuk peti kemas ekspor. Untuk peti kemas kosong waktu penyimpanan adalah 20 hari.

Атеш : Luasan yang diperlukan untuk satu TEUs yang tergantung pada sistem penanganan peti kemas dan jumlah tumpukan peti kemas di lapangan penumpukan, sepeti dijelaskan dalam Tabel 1.

BS : Broken stowage

Tabel 1 Luasan diperlukan per TEU

\begin{tabular}{|c|c|c|c|}
\hline \multirow{2}{*}{$\begin{array}{l}\text { Peralatan dan Metode } \\
\text { Penanganan }\end{array}$} & \multirow{2}{*}{$\begin{array}{c}\text { Tinggi/Jumlah } \\
\text { Penumpukan Peti } \\
\text { Kemas }\end{array}$} & \multicolumn{2}{|c|}{$\begin{array}{l}\text { Luasan Diperlukan per TEU ATEU } \\
\left(\mathrm{m}^{2} / \mathrm{TEU}\right)\end{array}$} \\
\hline & & PK 20 feet & PK 40 feet \\
\hline Trailer & 1 & 60 & 45 \\
\hline \multirow{3}{*}{ Truk forklift } & 1 & 60 & 80 \\
\hline & 2 & 30 & 40 \\
\hline & 3 & 20 & 27 \\
\hline \multirow{3}{*}{ Straddle carrier } & 1 & \multicolumn{2}{|c|}{30} \\
\hline & 2 & \multicolumn{2}{|c|}{15} \\
\hline & 3 & \multicolumn{2}{|c|}{10} \\
\hline \multirow{3}{*}{$\begin{array}{l}\text { Rubber Tyred Gantry Crane } \\
\text { / transtainer }\end{array}$} & 2 & \multicolumn{2}{|c|}{15} \\
\hline & 3 & \multicolumn{2}{|c|}{10} \\
\hline & 4 & \multicolumn{2}{|c|}{7,5} \\
\hline
\end{tabular}

Sumber: Triatmodjo (2010) 
Selanjutnya analisis data dengan menghitung rasio pemakaian lapangan penumpukan atau YOR dengan rumus perhitungan sebagai berikut :

$$
Y O R=\frac{\text { Total tonase barang di lapangan }}{\text { Holding capacity di lapangan }} \times 100 \%
$$

\section{HASIL DAN PEMBAHASAN}

\section{Pengumpulan Data Sekunder di TPK Koja}

Berdasarkan data yang diperoleh, dapat diuraikan gambaran umum tentang kondisi eksisting di TPK Koja sebagai berikut. Throughput peti kemas yang ditangani oleh TPK Koja tahun 2014 sampai dengan tahun 2016 dapat dilihat pada Tabel 2.

Tabel 2 Throughput peti kemas TPK Koja

\begin{tabular}{ccccc}
\hline \multirow{2}{*}{ No } & \multirow{2}{*}{ Peti Kemas } & \multicolumn{3}{c}{ Tahun } \\
\cline { 3 - 5 } & & $\mathbf{2 0 1 4}$ & $\mathbf{2 0 1 5}$ & $\mathbf{2 0 1 6}$ \\
\hline 1 & Import & 461.082 & 518.088 & 442.088 \\
\hline 2 & Export & 411.426 & 457.350 & 384.121 \\
\hline & Total : & $\mathbf{8 7 2 . 5 0 8}$ & $\mathbf{9 7 5 . 4 3 8}$ & $\mathbf{8 2 6 . 2 0 9}$ \\
\hline
\end{tabular}

Sumber : TPK Koja

Untuk total peti kemas impor dan ekspor pada tahun 2015 mengalami peningkatan throughput sebesar 11,79\% dibandingkan dengan tahun sebelumnya, sedangkan di tahun 2016 mengalami penurunan Throughput sebesar 15,29\%.

Lahan yang dimiliki oleh TPK Koja seluruhnya adalah seluas 32,73 hektar, luas tersebut terbagi menjadi beberapa area yaitu area dermaga dan area lapangan penumpukan, area office, workshop dan power house. Sedangkan kegiatan operasional yang dilayani oleh TPK Koja adalah container handling service yang terdiri dari ekspor, impor, transshipment dan vessel services, yang di dukung dengan fasilitas dan peralatan untuk pelaksanaan proses bongkar muat barang dan peti kemas, luas lapangan penumpukan di TPK Koja dapat dilihat pada Tabel 3 berikut.

Tabel 3 Lapangan penumpukan TPK Koja

\begin{tabular}{cccc}
\hline \multirow{2}{*}{ No } & \multirow{2}{*}{ Container Yard } & \multicolumn{2}{c}{ Spesifikasi } \\
\cline { 3 - 4 } & & Holding Capacity & Luas \\
\cline { 3 - 4 } & & TEUs & Ha \\
\hline 1 & Container Yard Import & 7.560 & 10.9 \\
\hline 2 & Container Yard export & 7.696 & 10.9 \\
\hline \multicolumn{2}{c}{ Total : } & 15.256 & $\mathbf{2 1 . 8 0}$ \\
\hline
\end{tabular}

Sumber: TPK Koja

Hasil perolehan data terkait dengan $d$ welling time peti kemas impor di TPK Koja disajikan pada Gambar 1 dan Gambar 2 berikut. 


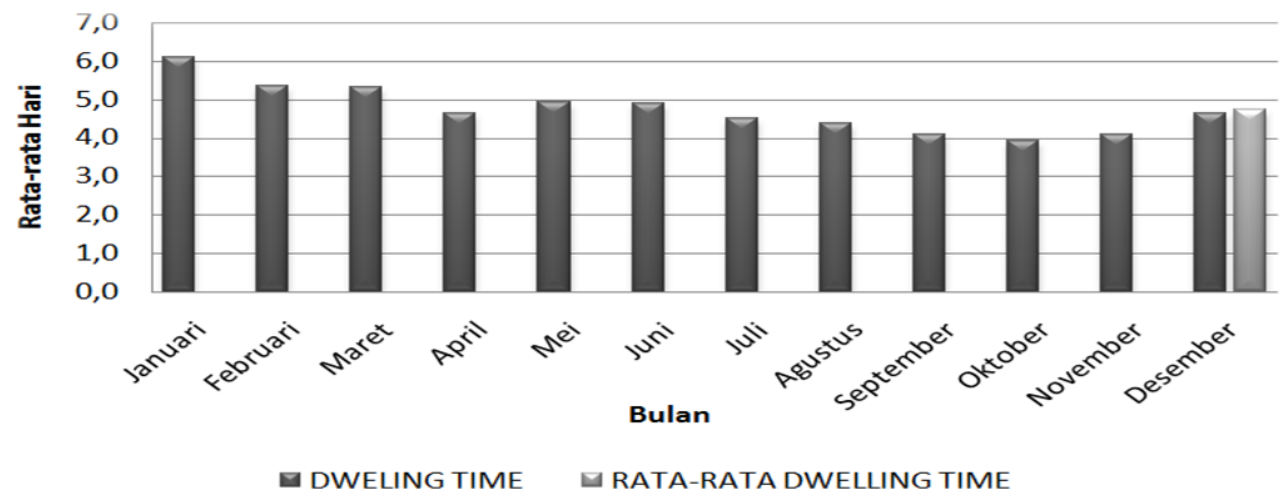

Sumber: PT Pelindo (2016)

Gambar 1 Dwelling time impor TPK Koja tahun 2015

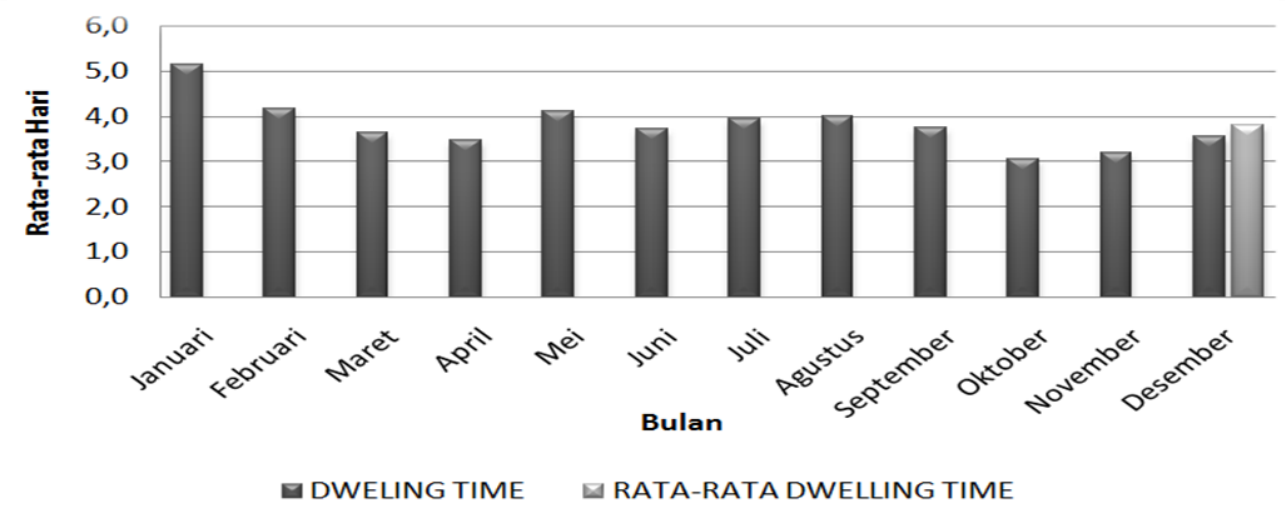

Sumber: PT Pelindo (2016)

Gambar 2 Dwelling time impor TPK Koja tahun 2016

Gambar 1 dan Gambar 2 menunjukan bahwa rata-rata dwelling time di TPK Koja pada tahun 2015 sebesar 4,7 hari dan tahun 2016 sebesar 3,8 hari.

\section{Hasil Perhitungan Lapangan Penumpukan Impor}

Tahapan analisis pada lapangan penumpukan impor dilakukan untuk mengetahui luas eksisting lapangan penumpukan yang terpakai dan kapasitas lapangan penumpukan (YOR) terhadap kelancaran arus peti kemas yang ditangani oleh TPK Koja saat ini, dengan menggunakan tahapan analisis sebagai berikut.

1. Perhitungan Luas Eksisting Lapangan Penumpukan yang Terpakai.

Merujuk Tabel 3 bahwa TPK Koja memiliki lapangan penumpukan peti kemas impor seluas 10.9 hektar. Hasil perhitungan luas eksisting lapangan penumpukan impor yang terpakai berdasarkan kondisi aktual saat ini di TPK Koja, sebagai berikut:

\section{Tahun 2015 :}

$$
A=\frac{518.088 \times 4.7 \times 7.5}{365(1-0,50)}=\frac{18.262 .602}{182.5}=100.069,05 \mathrm{~m}^{2}=10.007 \mathrm{Ha}
$$

\section{Tahun 2016 :}

$$
A=\frac{442.088 \times 3.8 \times 7.5}{365(1-0,50)}=\frac{12.599 .508}{182.5}=69.038,4 \mathrm{~m}^{2}=6.904 \mathrm{Ha}
$$


2. Perhitungan YOR

Merujuk Tabel 2 tentang Throughput di TPK Koja dan Tabel 3 tentang holding capacity impor sebesar 7.560 TEUs, sehingga perhitungan YOR sebagai berikut:

\section{Tahun 2015 :}

$Y O R=\frac{518.088}{7.560} \times 100=68,53 \%$

\section{Tahun 2016:}

$Y O R=\frac{442.088}{7.560} \times 100=58,47 \%$

Lapangan penumpukan impor yang dimiliki oleh TPK Koja adalah seluas 10,9 Ha, berdasarkan hasil perhitungan penggunaan lapangan penumpukan pada tahun 2015 yaitu seluas 10,007 Ha atau 91,81\% yang terpakai dan melayani arus peti kemas sebanyak 518.088 TEUs, hasil menunjukan bahwa tingkat kepadatan di lapangan penumpukan sudah sangat tinggi atau penggunaan lapangan penumpukan yang tersedia sudah mendekati kapasitas maksimal, kemudian pada tahun 2016 tingkat penggunaan lapangan penumpukan mengalami penurunan yaitu seluas 6,904 Ha atau 63,34\% yang terpakai dan melayani arus peti kemas sebanyak 442.088 TEUs.

\section{Pembahasan Lapangan Penumpukan Impor}

Berdasarkan hasil penelitian dan analisis, merujuk pada Gambar 1 dan Gambar 2 bahwa ratarata dwelling time TPK Koja di bulan Januari merupakan waktu terlama peti kemas mengendap di lapangan penumpukan, tingkat dwelling time pada tahun 2015 serta 2016 terlihat belum memenuhi standar yang telah ditetapkan oleh pemerintah selama 3 hari.

Terjadi penurunan tingkat kepadatan lapangan penumpukan di TPK Koja pada tahun 2016 disebabkan oleh dua faktor yaitu, dwellling time pada tahun 2016 menjadi lebih cepat dibandingkan tahun 2015 dan throughput peti kemas impor pada tahun 2016 mengalami penurunan sebesar 14,67\%.

Untuk hasil perhitungan YOR pada tahun 2015 menunjukan bahwa kapasitas lapangan penumpukan yang terpakai sebesar $68,53 \%$, hal ini menunjukan bahwa kapasitas lapangan penumpukan yang tersedia telah melewati batas standar yang telah ditetapkan oleh pemerintah atau masuk kedalam kategori kurang baik, sedangkan di tahun 2016 kapasitas penggunaan lapangan penumpukan dapat ditekan hingga $58,47 \%$ atau masuk kedalam kategori baik.

Dari hasil perhitungan luas eksisting lapangan penumpukan yang terpakai dan perhitungan YOR, ditemukan selisih hasil perhitungan terhadap tingkat penggunaan lapangan penumpukan di TPK Koja, selisih tersebut dapat dilihat pada Tabel 4 sebagai berikut.

Tabel 4 Selisih Hasil perhitungan lapangan penumpukan

\begin{tabular}{cccccc}
\hline Tahun & $\begin{array}{c}\text { Arus } \\
\text { Peti Kemas }\end{array}$ & DT & $\begin{array}{c}\text { Luas CY } \\
\text { Terpakai }\end{array}$ & YOR & Lag \\
\hline 2015 & 518.088 & 4,7 & $91,81 \%$ & $68,53 \%$ & $23,28 \%$ \\
\hline 2016 & 442.088 & 3,8 & $63,34 \%$ & $58,47 \%$ & $4,87 \%$ \\
\hline
\end{tabular}

Sesuai dengan Tabel 4 bahwa selisih hasil perhitungan pada tahun 2015 terlihat cukup signifikan yaitu sebesar 23,28\%, selisih tersebut diindikasikan bahwa TPK Koja dalam menetapkan besaran holding capacity terdapat komponen perhitungan YOR tidak didasari oleh kondisi aktual lapangan penumpukan impor saat ini. 
Untuk mendapatkan hasil perhitungan dan besaran holding capacity yang relevan, maka dapat diuraikan simulasi persamaan perhitungan terhadap penggunaan lapangan penumpukan sebagai berikut:

1) Jumlah arus peti kemas yang ditangani oleh TPK Koja pada tahun 2015 adalah sebanyak 518.088 TEUs, dengan tingkat pemakaian lapangan penumpukan sebesar $91,80 \%$ dan dwelling time sebesar 4,7 hari, maka 518.088:91,81 = 5.643,04 (5.643) holding capacity, rincian hasil simulasi persamaan perhitungan tahun 2015 dapat dilihat pada Lampiran 1, sehingga perhitungan YOR dapat terhitung sebagai berikut:

$Y O R=\frac{518.088}{5.643} \times 100=91,81 \%$

2) Jumlah arus peti kemas yang ditangani oleh TPK Koja pada tahun 2016 adalah sebanyak 442.088 TEUs, dengan tingkat pemakaian lapangan penumpukan sebesar 63,34\% dan dwelling time sebesar 3,8 hari, maka 442.088:63,34 = 6.979,60 (6.980) holding capacity, rincian hasil simulasi persamaan perhitungan tahun 2016 dapat dilihat pada Lampiran 2, sehingga perhitungan YOR dapat terhitung sebagai berikut:

$Y O R=\frac{442.088}{6.980} \times 100=63,34 \%$

Besaran holding capacity di tahun 2015 sebesar 5.643 dan tahun 2016 sebesar 6.980 merupakan perolehan berdasarkan komponen pada perhitungan luas eksisting lapangan penumpukan terpakai dengan kondisi lapangan penumpukan di TPK Koja yang sebenarnya. Perbedaan besaran holding capacity di tahun 2015 dan 2016 dipengaruhi oleh tingkat $d$ welling time di masing-masing tahun atau dengan kata lain bahwa tingkat dwelling time dapat mempengaruhi daya tampung lapangan penumpukan, semakin kecil tingkat $d$ welling time maka daya tampung lapangan penumpukan akan semakin besar.

\section{$>$ Perhitungan Luas Eksisting CY Terpakai :}

$$
A=\frac{574.672 \times 3 \times 7.5}{365(1-0,50)}=\frac{12.930 .120}{182.5}=70.849,97 \mathrm{~m}^{2}=7.085 \mathrm{Ha}(65 \%)
$$

\section{$>$ Perhitungan YOR :}

$$
Y O R=\frac{574.672}{8.841} \times 100=65 \%
$$

Apabila ilustrasi tersebut dibandingkan kondisi tahun 2015 dengan dwelling time selama 4,7 hari, penanganan peti kemas sebanyak 518.088 TEUs dan tingkat pemakaian lapangan penumpukan sebesar $91,81 \%$ terhadap regulasi yang berlaku saat ini, maka terjadi penurunan tingkat kepadatan di lapangan penumpukan sebesar 26,81\% serta peningkatan produktivitas peti kemas sebanyak 56.584 TEUs atau sebesar $10,92 \%$.

Dampak positif lain yang lebih luas bagi TPK Koja dengan mempersingkat waktu peti kemas di lapangan penumpukan menjadi 3 hari sesuai kebijakan pemerintah adalah meningkatnya kompetitif bisnis yang dapat dihandalkan dibandingkan dengan negara lain, serta tingkat kepercayaan pengguna jasa, merasakan adanya jaminan keamanan dan kenyamanan dalam melakukan bisnisnya di Indonesia. Hal ini senada dengan hasil penelitian Sitepu (2014); Maulana (2015); Kurniawan (2016); dan Witjaksono (2016).

Kebijakan pemerintah tentang $d$ welling time juga sejalan dengan kebijakan mutu dan terkandung pada visi misi yang dimiliki oleh TPK Koja yaitu senantiasa mengutamakan kepuasan pelanggan dengan menghasilkan dan menjaga agar jasa bongkar muat dan penumpukan peti kemas selalu tepat mutu, tepat waktu dan tepat jadwal dengan memenuhi peraturan dan perundangan yang berlaku. 


\section{KESIMPULAN DAN SARAN}

\section{Kesimpulan}

TPK Koja masih sangat beresiko terhadap kemungkinan terjadinya kepadatan arus peti kemas di masa mendatang, hal ini terlihat dari tingkat penggunaan lapangan penumpukan di TPK Koja yang belum mencapai standar regulasi pemerintah, TPK Koja dapat mempertimbangkan besaran $d$ welling time menjadi salah satu komponen dalam menetapkan besaran holding capacity, sehingga dapat mendukung tercapainya target produktivitas yang telah ditetapkan oleh TPK Koja setiap tahunnya dan ketaatan terhadap kebijakan pemerintah yang berlaku.

\section{Saran}

Saran dari penelitian ini, bahwa TPK Koja perlu melakukan evaluasi terhadap penetapan besaran Holding Capacity sesuai dengan kondisi real saat ini untuk mengukur kemampuan lapangan penumpukan agar mendapatkan tindakan penanggulangan terhadap kepadatan di lapangan penumpukan, serta mampu untuk menekan waktu peti kemas yang mengendap yaitu selama 3 hari sesuai dengan regulasi agar relevan dengan kondisi fasilitas yang dimiliki oleh TPK Koja dan kondisi lingkungan yang berkembang saat ini.

\section{DAFTAR PUSTAKA}

Artakusuma A. 2012. Evaluasi import container dwelling time di Pelabuhan Peti Kemas Jakarta International Container Terminal (JICT) Tanjung Priok. Jurnal online, Teknik Sipil.

Argiansyah R. 2016. Analisis Pengaruh Dwelling Time Terhadap Pendapatan, Studi pada PT. Terminal Peti Kemas Semarang tahun 2011-2015. Jurnal Administrasi Bisnis. 41(1).

[AEC] Asean Economic Community. 2015. Seminar Nasional peluang dan tantangan profesi ekspor dan impor dalam menghadapi Asean Economic Community (AEC) 2015.

Kurniawan A. 2016. Studi Kelayakan dan Strategi Pengembangan E-Business pada Inaportnet di Pelabuhan Makassar [tesis]. Bogor (ID). Institut Pertanian Bogor.

Lasse DA. 2014. Manajemen Kepelabuhanan. Jakarta (ID). Buku satu. PT RajaGrafindo Persada.

Maulana A. 2015. Analisis kapasitas Terminal Peti Kemas Pelabuhan Boom Baru Palembang. Jurnal online, Teknik Sipil Universitas Sriwijaya.

[Kemenhub] Kementerian Perhubungan. 2016. Peraturan Menteri Perhubungan Nomor 116 Tahun 2016 Tentang Pemindahan Barang yang Melewati Batas Waktu Penumpukan (long stay) di Pelabuhan Utama. Jakarta (ID): Kemenhub.

PT Pelabuhan Indonesia II (Pelindo II). 2016. Annual Report 2015 PT Pelindo II. Jakarta.

Rafi S, Purwanto B. 2016. Dwelling Time Management: Antara Harapan dan Kenyataan di Indonesia. Jurnal Manajemen Bisnis Transportasi dan Logistik. 2(2)

Sitepu G. 2014. Analisis Perbandingan kinerja Operasional Peti Kemas Makassar dan Bitung. Jurnal online, Teknik Sipil Universitas Hasanuddin.

Susanto B. 2014. Revolusi Transportasi. Jakarta (Indonesia). PT Gramedia Pustaka Utama.

Triatmodjo B. 2010. Perencanaan pelabuhan. Yogyakarta (ID): Beta offset.

Witjaksono A. 2016. Pengelolaan waktu endap dan tingkat kepadatan lapangan penumpukan peti kemas di PT, Jakarta International Container Terminal (JICT). Jurnal Manajemen Tehnologi, Vol.15 (No.1): 11-35. 
Lampiran 1 Perhitungan luas eksisting lapangan penumpukan terpakai \& YOR, Dwelling time 4,7 hari, tahun 2015.

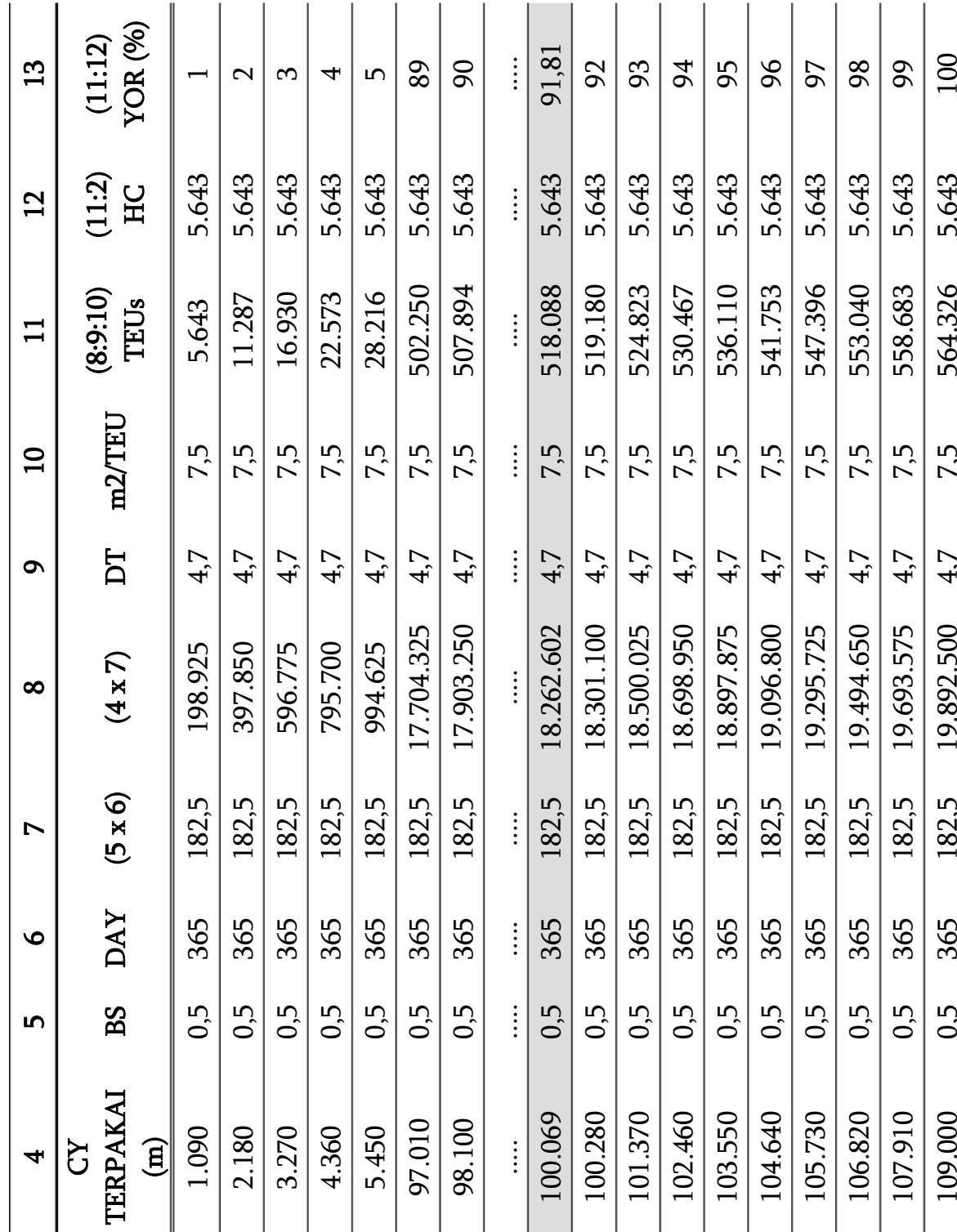

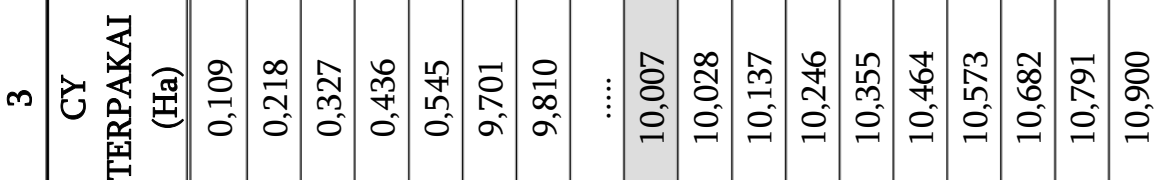

$\$$

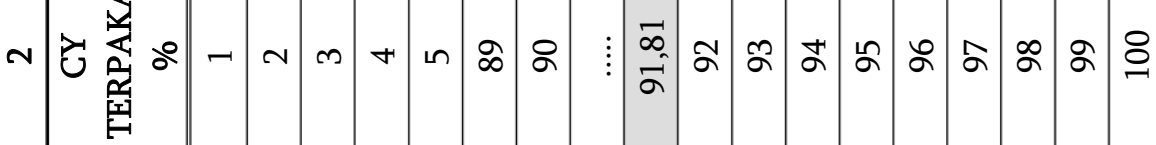

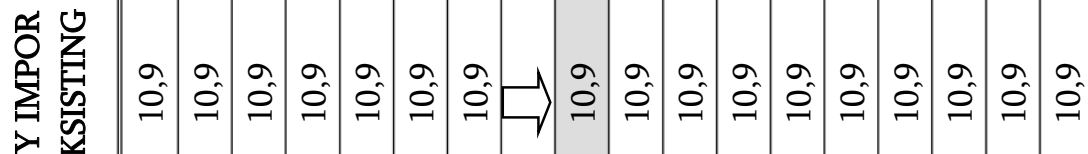


Lampiran 2 Perhitungan luas eksisting lapangan penumpukan terpakai \& YOR, dwelling time 3,8 hari, tahun 2016.

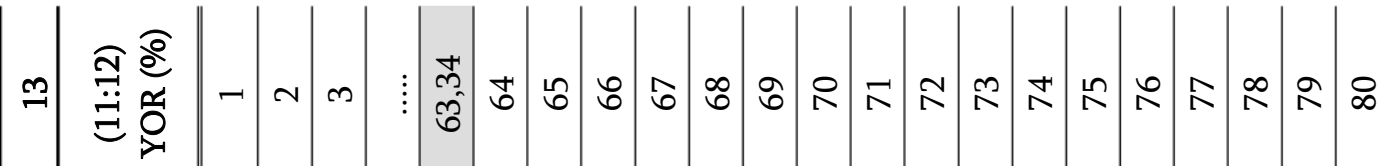

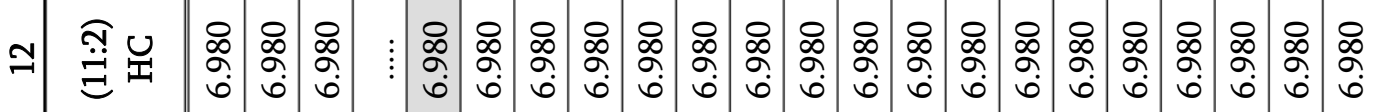

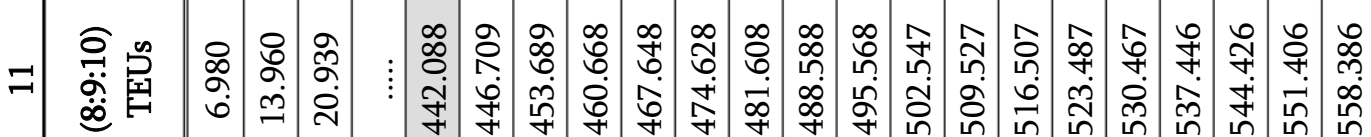

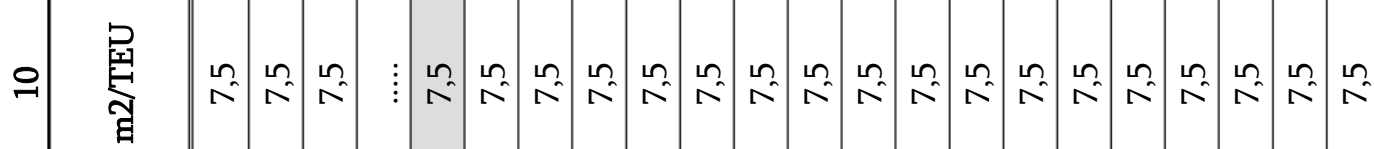

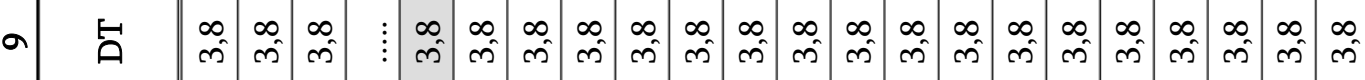

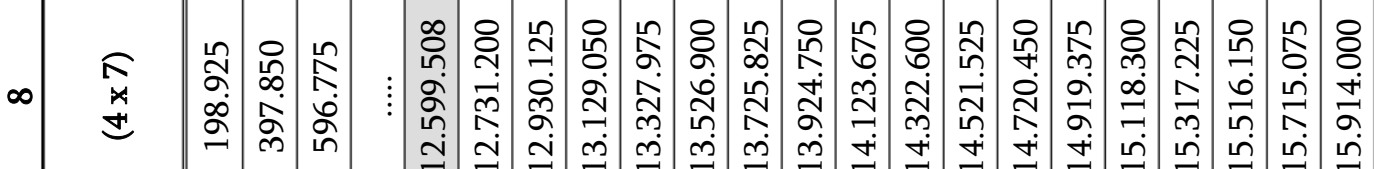

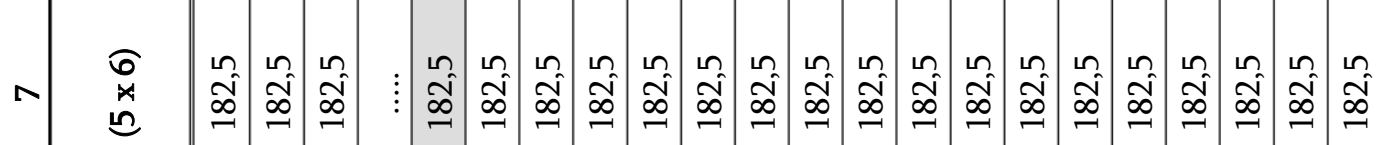

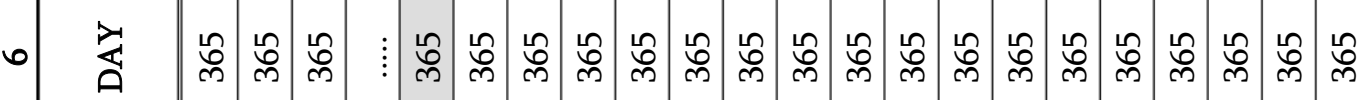

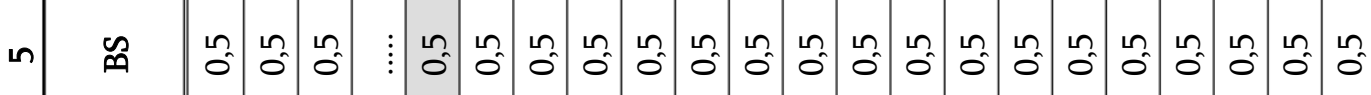 在

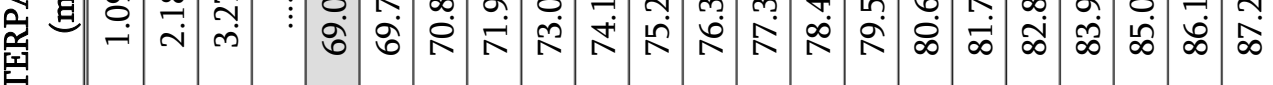
度

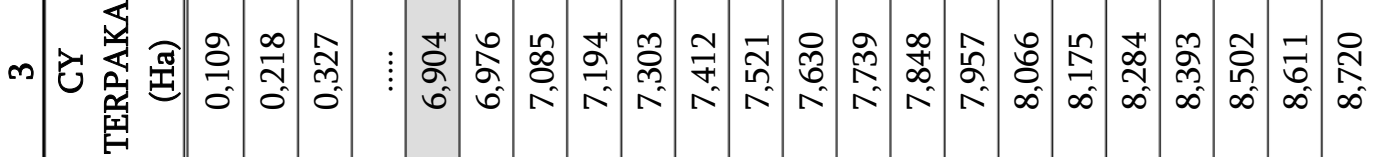

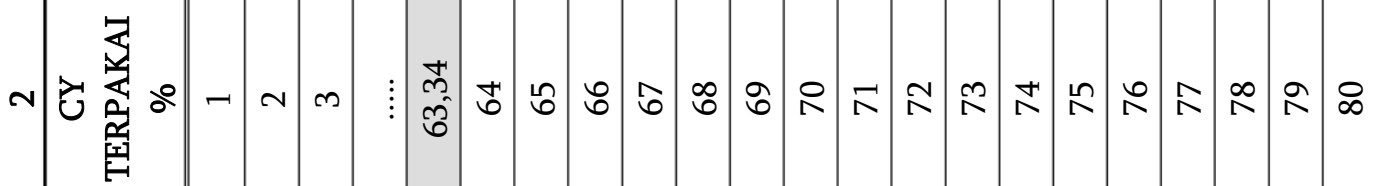

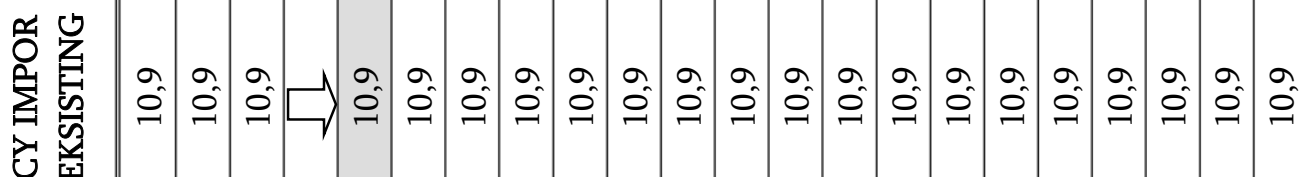


Lampiran 2 Perhitungan luas eksisting lapangan penumpukan terpakai \& YOR, $d$ welling time 3,8 hari, tahun 2016 (lanjutan).

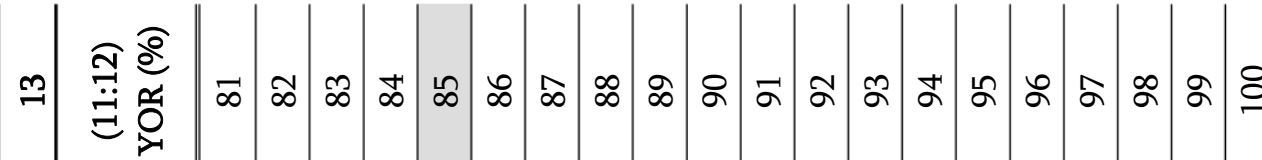

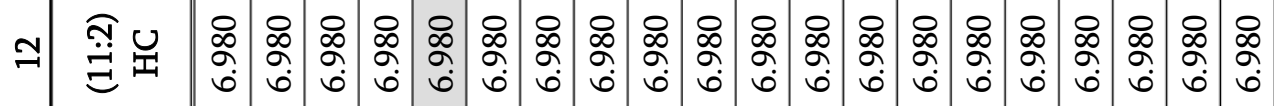

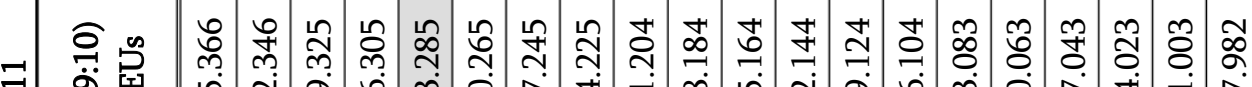
家

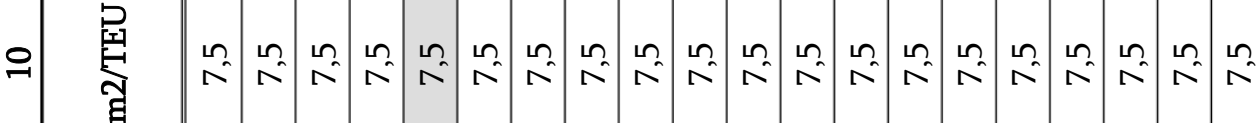

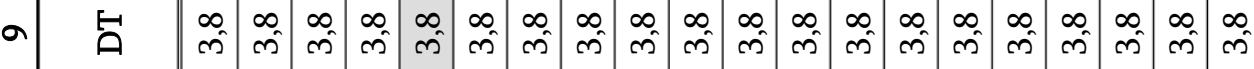

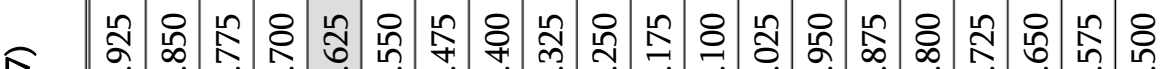

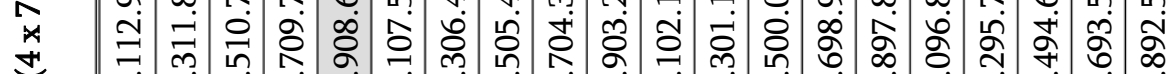

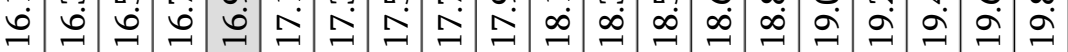

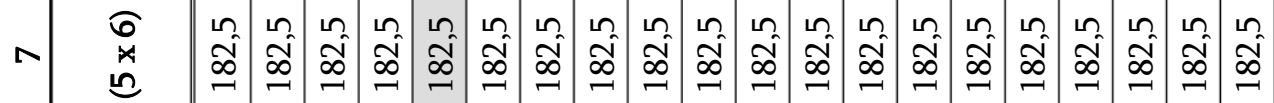

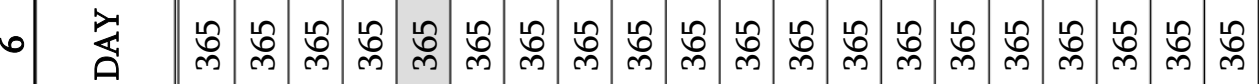

in

m

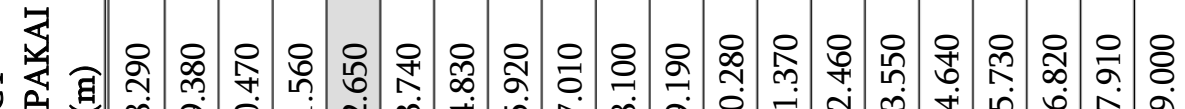

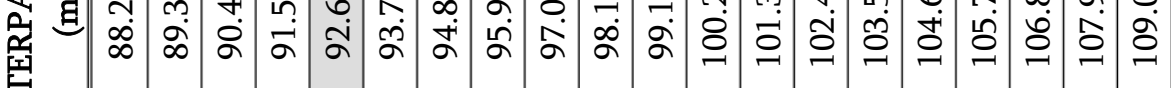

疋

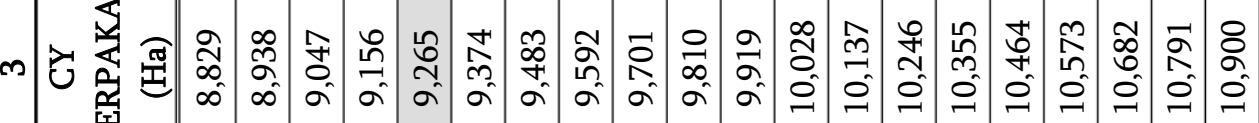
폭

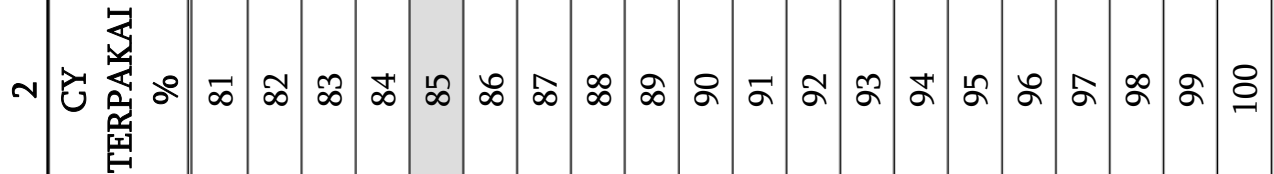

ㄸำ

- 䓪 